\title{
Experimental observations on the different mechanisms for solid ejection in gas-fluidized beds
}

\author{
J.A. Almendros-Ibáñez ${ }^{\mathrm{a}, \mathrm{b}, *}$, S. Sánchez-Delgado ${ }^{c}$, C. Sobrino ${ }^{c}$, D. Santana ${ }^{\mathrm{c}}$ \\ a Escuela de Ingenieros Industriales, Dpto. de Mecánica Aplicada e Ingeniería de Proyectos, Universidad de Castilla La Mancha, Campus Universitario, 02071, Albacete, Spain \\ ${ }^{\mathrm{b}}$ Renewable Energy Research Institute, Avda. de la Investigación s/n, 02071, Albacete, Spain \\ c Universidad Carlos III de Madrid, ISE Research Group, Thermal and Fluid Engineering Department, Avda. de la Universidad 30, 28911 Leganés, Madrid, Spain
}

\begin{abstract}
A B S T R A C T
This work presents an experimental study of the ejection velocity for different mechanisms of solid ejection in fluidized beds. The experiments were carried out in a 2D fluidized bed, where the bubble eruptions were recorded with a frequency of 250 frames per second using a high speed video camera with a resolution of 1.3 Megapixels.

The results show that in isolated bubble eruption, the dome velocity is significantly reduced by the effect of a group of raining particles in the form of stalactites within the bubble. Higher velocities are observed when bubble coalescence takes place. If bubbles coalesce before the leading bubble breaks, the momentum of the trailing bubble together with the increase in the throughflow accelerate the dome of the leading bubble. In contrast, when coalescence occurs after the breakage of the leading bubble, the wake of the trailing bubble is projected into the freeboard with a very high velocity (wake spike mechanism). The last observed mechanism, the jet spike mechanism, occurs when a stream of bubbles reaches the bed surface following the path opened by the previous bubbles. A cloud of particles moving upward is observed, although their velocities are not as high as in the wake spike mechanism due to the interchange of momentum during the collisions with other particles.

Finally, an explanation for some of the patterns of gas release from erupting bubbles recently observed by Hartung et al. [G. Hartung, C.R. Müller, J. Hult, J.S. Dennis, C.F. Kaminski, Laser diagnostic investigation of the bubble eruption patterns in the freeboard of fluidized beds. 1. Optimization of acetone planer laser induced fluorescence measurements. Ind. Eng. Chem. Res. 47 (2008) 5686-5697] is proposed.
\end{abstract}

\section{Introduction}

Entrainment and/or elutriation are important phenomena in fluidized beds. Entrainment refers to the total flux of bed material carried out of the bed while elutriation is the outward flux of solids of a specific size, typically fine particles. Although in fluidized bed reactors the chemical reactions or the drying process could occur mainly in the dense phase, the freeboard usually takes up most of the bed volume in industrial units [1]. The height of the freeboard is usually chosen to prevent the loss of a large amount of bed material by the gas flow, although in some cases, the height of the freeboard could be determined by other factors. For example, the height could be controlled by the need to have enough gas residence time to

\footnotetext{
* Corresponding author at: Escuela de Ingenieros Industriales, Dpto. de Mecánica Aplicada e Ingeniería de Proyectos, Universidad de Castilla La Mancha, Campus Universitario, 02071, Albacete, Spain. Tel.: +34 967555320/1256; fax: +34 967555321.

E-mail address: jose.almendros@uclm.es (J.A. Almendros-Ibáñez).
}

complete the reactions in biomass gasifiers [2,3] or to control the particle flux for the proper design of separation equipments such as cyclones and filters [4].

Regarding particle entrainment, the flux of elutriated particles within a discrete particle size range $i$, with a mean particle diameter $d_{p_{i}}$, can be defined as

$E_{i}=\frac{\int_{A} \overline{\rho_{i}} v_{i} d A}{\int_{A} d A}$,

where $\overline{\rho_{i}}=(1-\epsilon) \rho_{p}$ is the mass of solids of size $d_{p_{i}}$ per bed volume at one determined height, $v_{i}$ is the upward velocity and $A$ is the cross-sectional area of the bed. Therefore, the total mass of solids carried out is

$E=\sum_{i} E_{i}$

The entrainment flux varies with height over the bed surface $h$. Kunii and Levenspiel [5] represented the complex phenomena of the particle flow in the freeboard with a simple model in which 
the solids are divided into three phases: dispersed solids moving up, agglomerates of solids moving up and agglomerates and a thin-walled layer of particles moving down. In this way, $E$ varies exponentially with $h$ according to

$\frac{E-E_{\infty}}{E_{0}-E_{\infty}}=\exp (-a h)$,

where the constant $a$ can be estimated as $a \approx 4 \mathrm{~m}^{-1}$ if no detailed information is available [6], and $E_{\infty}$ and $E_{0}$ represent the flux of solids elutriated from a very tall bed and the flux projected from the bed surface, respectively.

The flux $E_{\infty}$ can be defined as the flux of particles that have a terminal velocity $u_{t}$ lower than the superficial gas velocity $U$, although experimental results show some discrepancies [1]. The height over the bed surface at which the flux of particles is equal to $E_{\infty}$ is known as the transport disengaging height (TDH). If the height of the bed $H$ is longer than the TDH, the flux of solids elutriated does not vary with $h$ and is equal to $E_{\infty}$. Different correlations can be found in the literature to calculate $E_{\infty}$, although differences of one order of magnitude can be observed between them. A summary of the most common correlations expressed in SI units can be found in [1].

At the bed surface, the initial flux of ejected particles $E_{0}$ depends on the mean density at that level, which can be approximated as $\overline{\rho_{i 0}}=\left(1-\epsilon_{m f}\right) \rho_{p}$ [7-9], and on the particle ejection velocity $v_{0}$, which is related with the bubble velocity [10-13]. There are fewer experimental studies in the literature about $E_{0}$ because of the difficulty of accurately measuring this flux. Pemberton and Davidson [8] extrapolated the $E_{0}$ Eq. (3) to $h=0$ using experimental data of different researchers, although this process of obtaining $E_{0}$ is not very accurate due to the uncertainty in the exact position of $h=0$ in a bubbling bed. Wen and Chen [6] developed an expression for $E_{0}$ by adjusting the following equation to data from different studies:

$E_{0}=3.07 \times 10^{-9} \frac{\rho_{g}^{3.5} g^{0.5}}{\mu^{2.5}} A D_{b}\left(U-U_{m f}\right)^{2.5}$

Some years later, Choi et al. [14] extended Eq. (4) including the influence of bed temperature on the flux of particles $E_{0}$.

However, Eq. (4) does not take into account the origin of the projected particles. Several theories have been discussed over the years about the origin of the projected particles. Some authors consider the bubble roof (or bubble dome/nose) as the dominant mechanism $[7,15,16]$ while others suggest that most of the elutriated particles come from the bubble wake [17-19]. Pemberton and Davidson [8] developed two different models of particle ejection: from the roof and from the wake of the bubble. They showed how the wake model predicts values of $E_{0}$ one order of magnitude higher than the roof model for the same superficial gas velocity, and they concluded that for group B particles with $U / U_{m f}<10-15$ the roof model is suitable, while for group A particles and group B with $U / U_{m f}>10-15$, the projection from the wake dominates due to the increase of bubble coalescence at the bed surface. In contrast, the Smolders and Baeyens model [9] predicts much higher values of $E_{0}$ assuming that the particles are projected from the bubble roof, in contrast with the results of Pemberton and Davidson.

Therefore, the ejection mechanisms and the origin of the elutriated particles in fluidized beds are still not completely understood. Moreover, the mechanisms of solid ejection from the bed surface are not only the bubble roof and bubble wake. Levy et al. [20] undertook an extensive study about the different mechanisms for solid ejection in 2D and 3D fluidized beds and observed four different mechanisms:

(1) Bulge bursting mechanism, the most common. The bulge layer is projected when the bubble reaches the bed surface, whereas the height attained by the particles is somewhat less than the bubble diameter and the bubble wake remains intact.

(2) The double bubble mechanism occurs when two bubbles coalesce at the bed surface and the middle layer of solids between the leader and the trailing bubble is projected together with the leading bulge.

(3) The wake spike mechanism occurs when two or more bubbles coalesce at the bed surface and the wake of the trailing bubble is projected in the form of a spike.

(4) The jet spike mechanism occurs when two or more bubbles coalesce at the bed surface and the bubbles form a flow passage that transports solids from the bed, projecting them into the freeboard.

The last three mechanisms are related to bubble coalescence. Although they are less frequent [20], the velocity of the projected particles when coalescence occurs is higher than in isolated bubbles [10].

This work tries to clarify some aspects of the different mechanisms for solid ejection observed by Levy et al. [20]. In particular, this article is focused on the particle ejection velocity, which has been observed to be much higher when bubble coalescence is involved. Therefore, the particles projected with these mechanisms, although they are less frequent, could attain higher heights in the freeboard and consequently could be the main cause of elutriation and entrainment. In addition, an explanation for some patterns of gas release from erupting bubbles observed by Hartung et al. [21], based on the stalactite effect observations, is given.

In the remainder of the paper, the experimental set-up is briefly described. Then, different mechanisms of solids ejection are analyzed in this order: isolated bubbles, two coalescing bubbles, wake spike and jet spike. In Section 7 the gas mixing in the splash zone and the different mechanisms of gas release from erupting bubbles are explained from the view of the results obtained for isolated bubble eruptions. Finally, the main conclusions of the work are presented and discussed.

\section{Experimental set-up}

The experiments were carried out in a 2D fluidized bed $(110 \mathrm{~cm}$ width $\times 60 \mathrm{~cm}$ height $\times 0.5 \mathrm{~cm}$ thickness) made with two glass-walls that allow the user to see its interior. The bed was illuminated with two $650 \mathrm{~W}$ spot-lights from the front of the bed, with a dark background at the rear in order to attain high contrast between the white particles and the regions free of particles (bubbles and freeboard). Bubble eruptions at the bed surface were captured using a high speed video camera with a resolution of $1280 \times 1024=1.3$ Megapixels. The pictures were captured from the central region of the bed at a rate of $250 \mathrm{fps}$, although the exposure was only $1 / 5000 \mathrm{~s}$ in order to properly detect the bubble contour and prevent blurring due to the bubble motion.

Spherical glass particles with a mean particle diameter of $350 \mu \mathrm{m}$ and a density of $2500 \mathrm{~kg} / \mathrm{m}^{3}$ (type B according to Geldart's classification [22]) were fluidized with air. The height of the fixed bed was approximately $30 \mathrm{~cm}$, and the superficial gas velocity during the experiments was varied between $1 \leq U / U_{m f} \leq 2$. Higher velocities were avoided in order to prevent the entrainment of solids from the bed.

In order to avoid influences of the air-supply system in the bubble eruption pattern, the distributor pressure drop must be high enough to assure that the bed and the air-supply system are uncoupled $[23,24]$. In this way, the distributor used during experiments was a perforated plate with 110 holes $1 \mathrm{~mm}$ in diameter with a $1 \mathrm{~cm}$ 


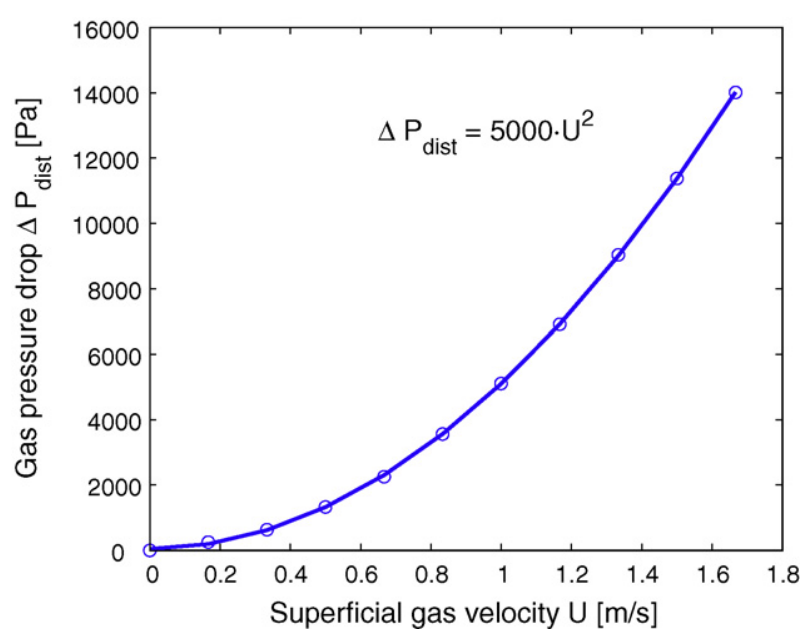

Fig. 1. Characteristic curve of the distributor.

gap between each, resulting in a fraction of $1.57 \%$ of open area, with the characteristic curve showed in Fig. 1.

The gas pressure drop through the bed is $\Delta P_{\text {bed }} \simeq 4000 \mathrm{~Pa}$ and the superficial gas velocity during experiments was around $1 \mathrm{~m} / \mathrm{s}$. Therefore, the distributor and the bed pressure drops during experiments were of the same order. Under similar conditions Johnsson et al. [23] and Sasic et al. [24] showed that bed operates under the multiple bubble regime and the bed and the air-supply system are independent.

\section{Isolated bubble eruption: the stalactite effect}

When an isolated bubble reaches the bed surface, it projects the solids from the dome formed during the eruption process. Usually, the bubble wake is not projected unless there is another bubble of similar or higher size coalescing below when the leading bubble breaks the bed surface.

Before obtaining the initial particle velocity of the ejected particles, the instant when the bubble breaks the bed surface needs to be determined. There is no general agreement on the definition of this time. Pemberton and Davidson [8] assumed that the bubble dome is projected into the freeboard when the dome thickness is equal to the particle diameter. In contrast, in $2 \mathrm{D}$ fluidized beds, the dome thickness is typically much higher than the particle size $[15,25]$. Müller et al. [26] defined the eruption instant as the time when the vertical velocity of the dome nose reaches its maximum, which corresponds approximately to a ratio between the dome thickness and the particle diameter of $\delta / d_{p} \sim 3$ under their experimental conditions. Santana et al. [12] and Almendros-Ibáñez et al. [13,25] defined the eruption instant as the time when the bubble dome is broken and the bubble interior and the freeboard become connected. The same criteria will be followed in this work. The evolution of the external surface of the bubble dome will be followed during the eruption process until the bubble dome breaks at a certain point due to the instabilities that appear before its breakage.

Fig. 2 shows three frames of one isolated bubble erupting at the bed surface. At $t=0 \mathrm{~ms}$ the bubble approximates the bed surface forming the typical dome. Then, 56 ms later, the nose of the bubble is over the mean bed height and the external surface of the dome is still smooth. At $t=124 \mathrm{~ms}$, the bubble dome breaks the bed surface. The dome contour at this moment is not smooth, and irregularities appear due to the effect of the stalactites, which funnel the particles situated in the bubble dome. A similar eruption process was observed by Müller et al. [26] for isolated injected bubbles.

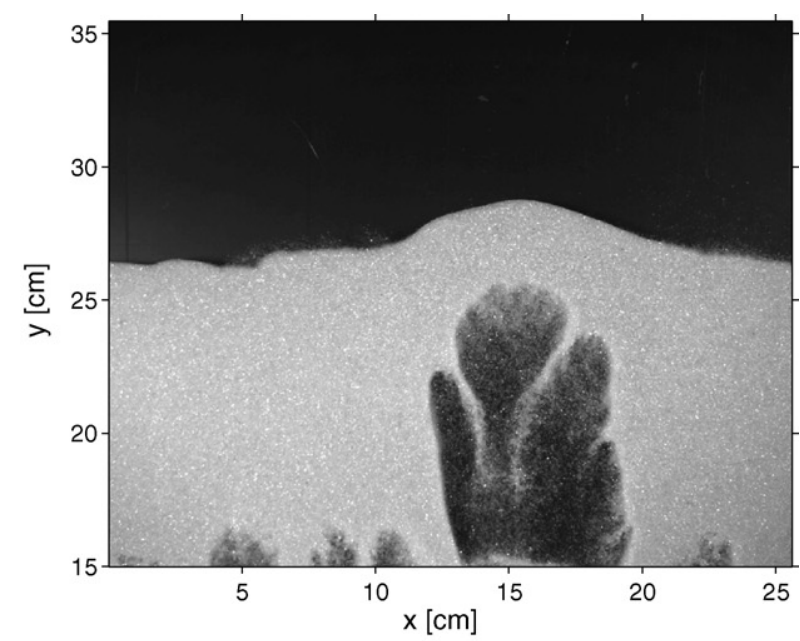

(a) $t=0 \mathrm{~ms}$

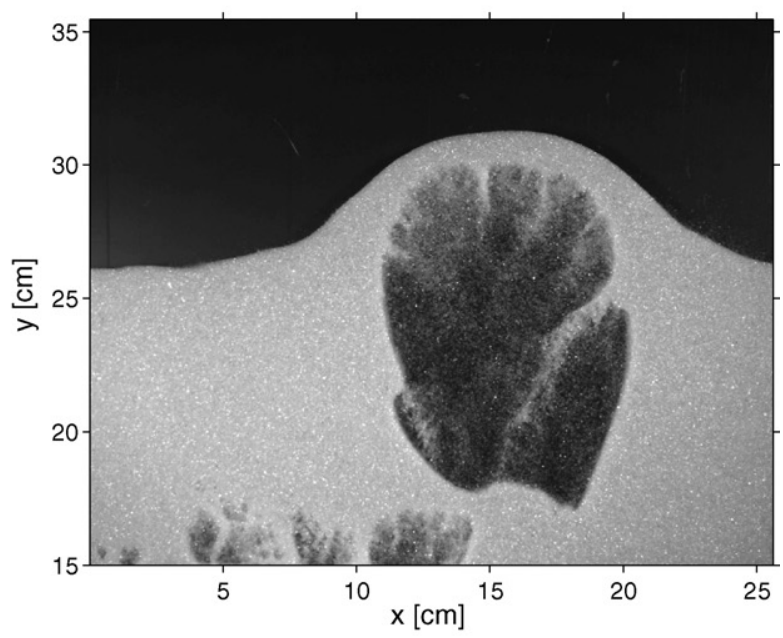

(b) $t=56 \mathrm{~ms}$

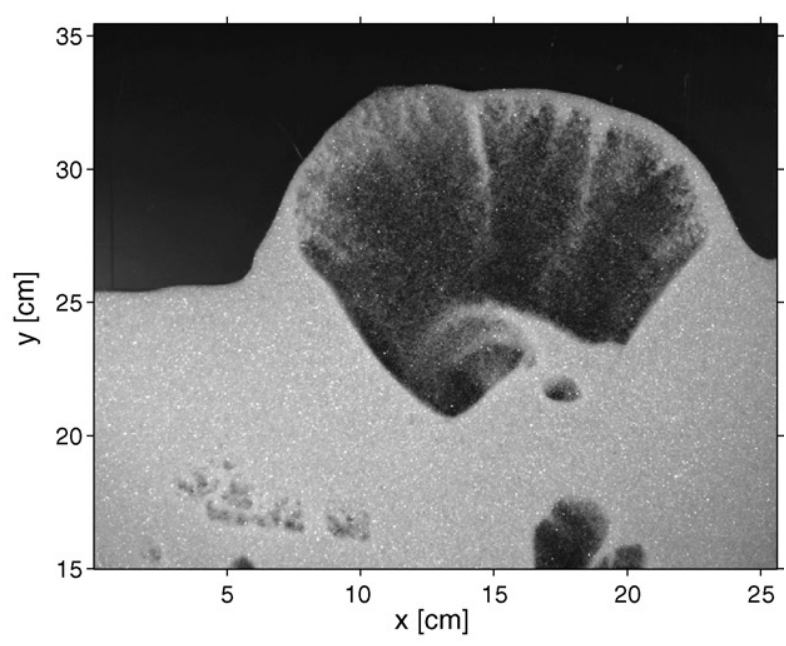

(c) $t=124 \mathrm{~ms}$

Fig. 2. Evolution of one isolated bubble breaking at the bed surface: (a) $t=0 \mathrm{~ms}$; (b) $t=56 \mathrm{~ms}$; (c) $t=124 \mathrm{~ms}$. 

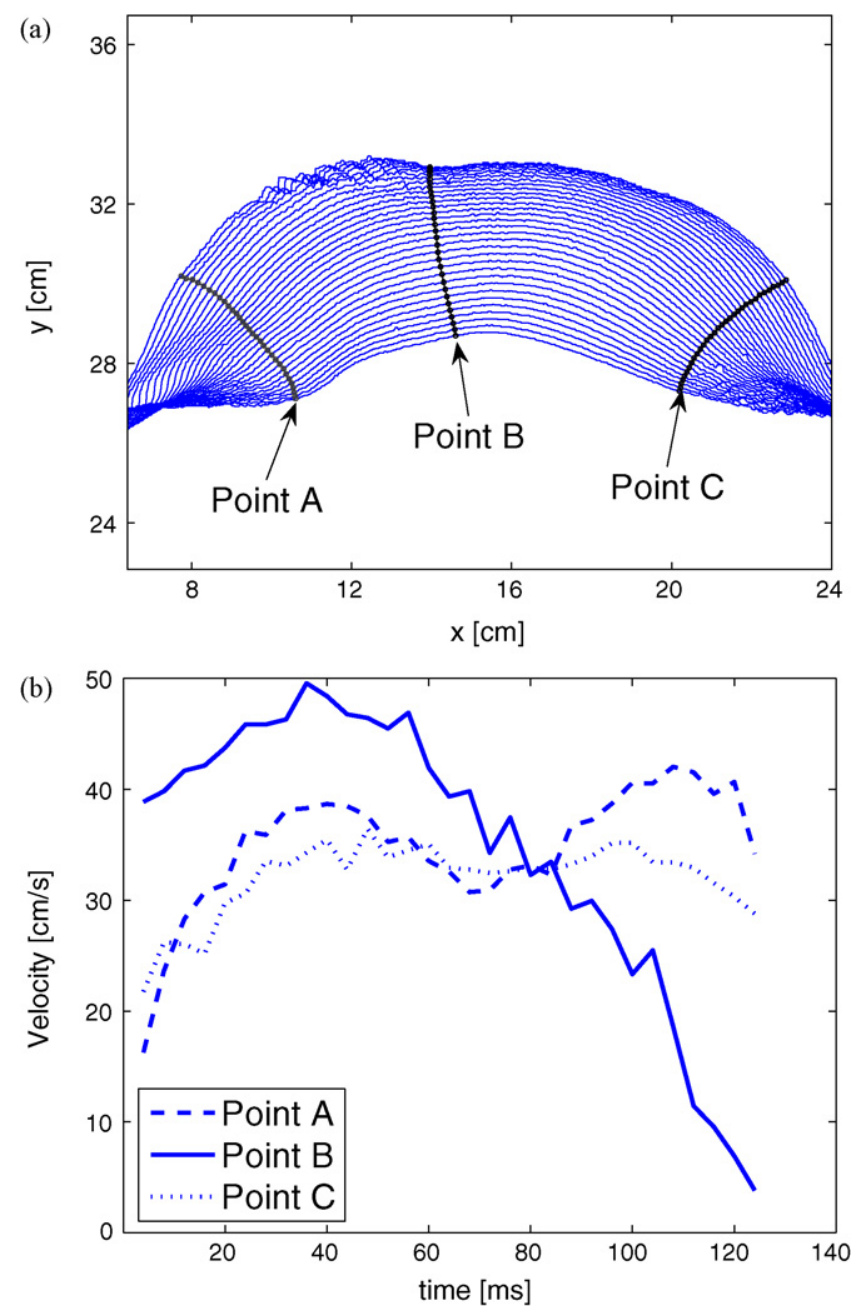

Fig. 3. (a) Evolution of the external surface of the bubble dome each $4 \mathrm{~ms}$ and (b) velocity of the points $A, B$ and $C$.

In order to follow the evolution of the dome contour, the grey pictures were transformed into black and white pictures with a threshold value. Different methods can be found in the literature to obtain the optimum threshold from a grey picture [27]. From all of them, Otsu method [28] is widely used due to its simplicity and stability. The method assumed that the pixels are separated in two classes (black and white colors) and obtain the optimum threshold as the one that maximize the between-class variance. According to Gonzales-Barron and Butler [27], Otsu method obtains optimal threshold values compared to others. Thus, this method was used to determine bubble and freeboard contours in this work.

The external surface of the dome formed during the bubble eruption was followed until the dome breaks at a certain point. Fig. 3(a) shows the evolution of the external surface of the dome during the bubble eruption process for the isolated bubble shown in Fig. 2. The evolution is captured during 32 consecutive frames (128 ms). The contour of the dome is smooth in the first 20-25 frames. Then, some irregularities appear in the central region of the dome, where the particle displacement is vertical. Finally, the dome collapses and the bubble breaks.

The irregularities in the dome contour are caused by the rain of particles in the interior of the bubbles in the form of stalactites, which can divide the bubble in two [29]. The effect of these stalactites on the bubble dome becomes more important as the dome thickness decreases. Fig. 2(b) shows one stalactite at the bubble

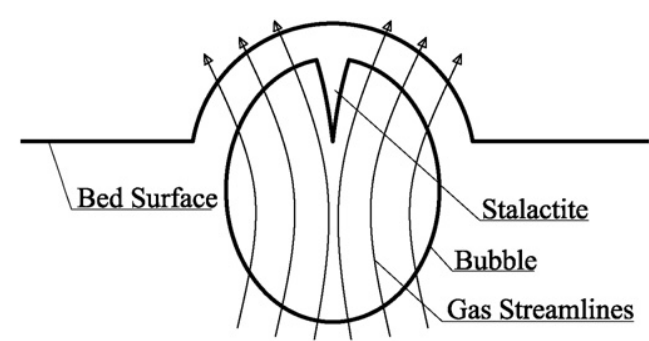

Fig. 4. Scheme of the gas streamlines when one isolated bubble erupts at the bed surface with a group of particles raining in the form of a stalactite.

nose, which funnels the particles situated between the bubble contour and the free surface of the bed, although the free surface of the bed is not affected by this rain of particles and it remains smooth. In contrast, as the bubble ascends and the dome thickness decreases, the particles at the external surface of the dome are funneled by the stalactite, and the irregularities appear at the contour of the dome.

The stalactite influence can be observed more clearly plotting the particle velocity at the dome contour. Fig. 3(b) shows the velocity of one point situated at the nose of the dome (point $B$ ) and another two points (points $A$ and $C$ ) located at the edges of the dome. The velocity of each point is obtained by tracing the perpendiculars from the points $\mathrm{A}, \mathrm{B}$ and $\mathrm{C}$ at $t=0$ (Fig. 2(a)). The intersections of these lines with the contour of the next frame $(t=4 \mathrm{~ms}$ ) defines the displacement of each point at $t=0$. The same procedure between frames is repeated until the bubble dome breaks the bed surface at $t=124 \mathrm{~ms}$ (Fig. 2(c)). The intersection points obtained in each contour are plotted in Fig. 3(a).

The velocity of point $B$ is vertical, although the velocity of points $A$ and $C$ have an appreciable horizontal component, especially during the last several frames. Point B accelerates until $t=40 \mathrm{~ms}$, when it reaches its maximum velocity and then decelerates with a rate of approximately $\sim-7 \mathrm{~m} / \mathrm{s}^{2}$. In contrast, points $A$ and $C$, which are not directly affected by the stalactite, show a different evolution. They initially accelerate as point B does until $t=40 \mathrm{~ms}$. Then, their velocity seems to decrease slightly, but they finally accelerate again and maintain their velocity over $30 \mathrm{~cm} / \mathrm{s}$.

The rain of particles in the form of stalactites at the bubble nose suggests that the flow of air crossing the bubble (throughflow) deviates its path. Since the throughflow cannot drag the particles of the stalactite, the flow deviates and drags the particles situated at the sides of the dome, which are projected with higher velocities than the particles situated at the central region of the dome. Fig. 4 shows a sketch of the process. Thus, in isolated erupting bubbles, whose dominant mechanism of particle ejection is the bulge bursting mechanism, when particles in the form of stalactites rain from the bubble dome, the vertical velocity of the particles is very low because of they are funneled by the stalactite. Higher velocities are reached by the particles situated at the edges, although their velocity has an appreciable horizontal component, and consequently, they have a low probability of reaching high heights in the freeboard.

Fig. 5 shows more examples of isolated erupting bubbles, which all exhibit a similar behaviour. The points of the external surface of the dome situated over one stalactite (solids lines in Fig. 5(b), (d) and (f)) initially have a high velocity, although as the dome thickness decreases, they decelerate progressively until the dome breaks. In contrast, the points situated at the sides of the dome or between two stalactites (see point B in Fig. 5(e)), plotted in dotted lines in Fig. 5(b), (d) and (f) initially have a lower velocity. However, these points do not decelerate as much and maintain a higher velocity at the moment of eruption. In fact, some points even accelerate (point D in Fig. 5(b)). 

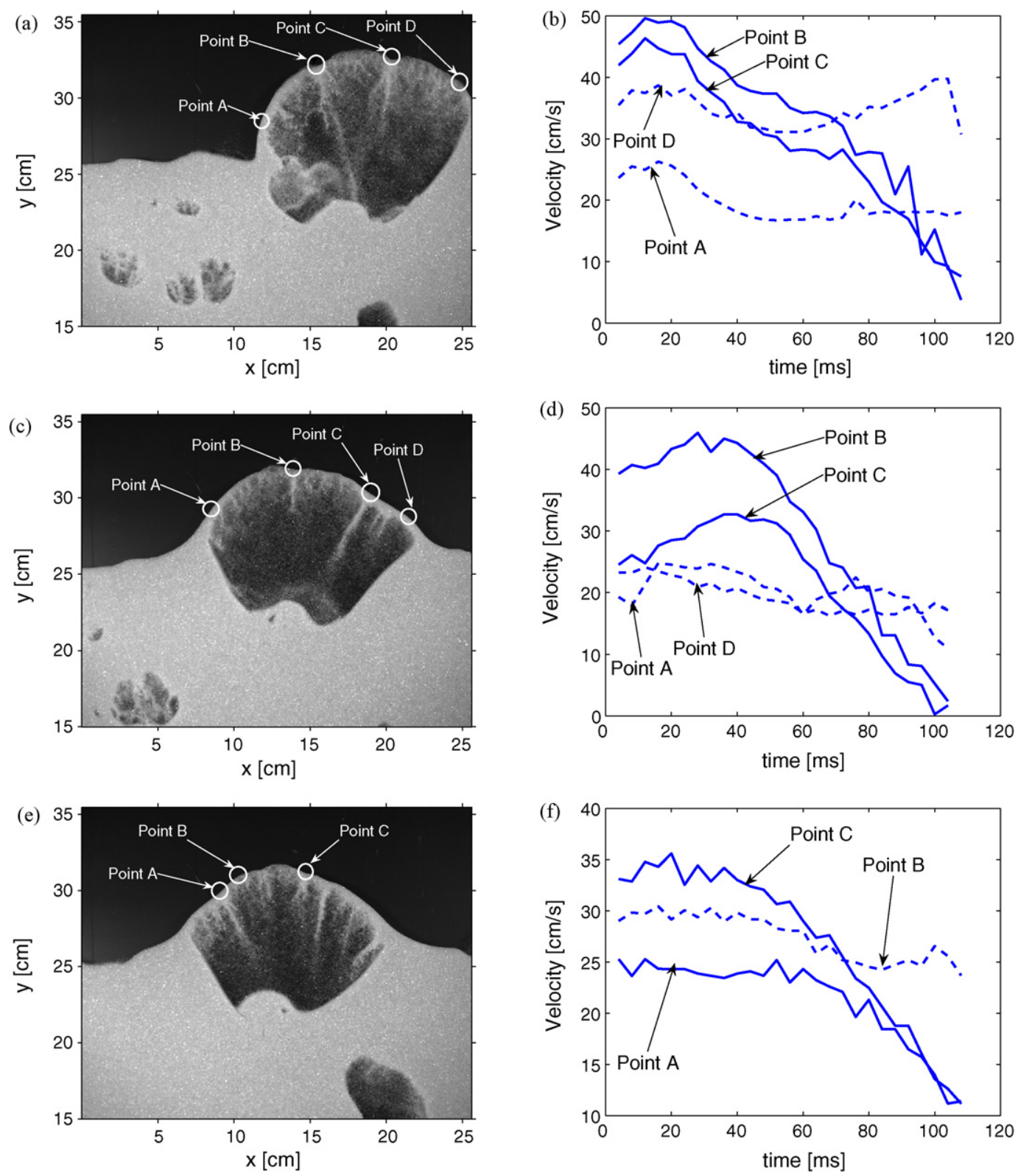

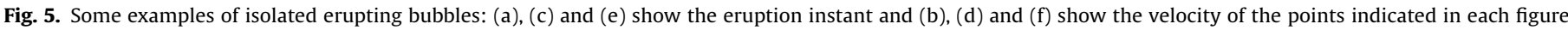
during the eruption process.

\section{Two bubbles coalescing at the bed surface}

When two bubbles coalesce while the leading one erupts at the bed surface, not only the middle layer of solids is projected to the freeboard. Also, the bulge of particles in the dome of the leading bubble is accelerated and projected at high velocities.

Fig. 6 shows two bubbles coalescing at the bed surface when the leading bubble is erupting. Point $A$ is situated just over one stalactite, while point $B$ is on the bubble nose. Unlike the case of one isolated bubble, in this case the bubble dome is accelerated notably by the momentum transferred by the trailing bubble. The coalescence takes place approximately at $t \approx 20 \mathrm{~ms}$. Point A accelerates until $t \approx 60 \mathrm{~ms}$, when it reaches its maximum velocity and then decelerates until a velocity approximately equal to its initial one. Point B shows a similar evolution, although this reaches a higher velocity (almost $90 \mathrm{~cm} / \mathrm{s}$ ), and its final velocity is double the velocity at $t=20 \mathrm{~ms}$. At $t=100 \mathrm{~ms}$ the leading bubble breaks the bed surface.
The dome of the leading bubble is not simply accelerated by the momentum transferred by the trailing bubble. When both bubbles coalesce, an elongated region that is highly permeable to gas flow is formed just under the bed surface. This cavity diverts the gas trajectory and the gas reaches the freeboard crossing the bubble due to the more favourable pressure gradient. The throughflow increases with the bubble aspect ratio because the pressure gradient, which forces the gas to flow, also increases [30]. Thus, when two bubbles coalesce, a significant increase of the throughflow accelerates the particles of the bubble dome and projects them to the freeboard with higher velocities than in the isolated bubble mechanism.

\section{Wake spike mechanism}

The wake spike mechanism for solid ejection observed by Levy et al. [20] typically occurs when two or more bubbles coalesce consecutively at the bed surface and the wake of the trailing bubble is projected into the freeboard in the form of a spike. 

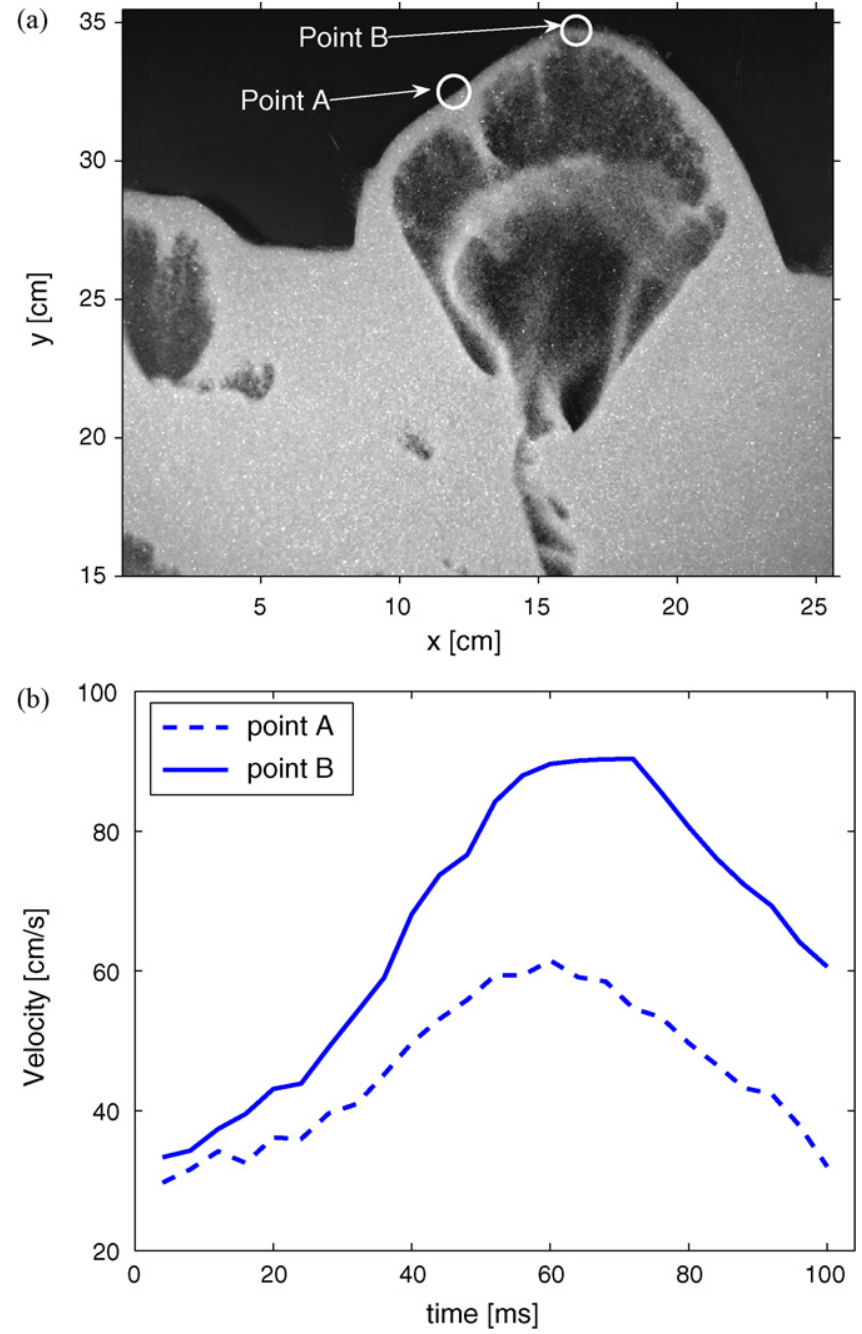

Fig. 6. (a) Two bubbles coalescing at the bed surface and (b) velocity of the points $\mathrm{A}$ and $\mathrm{B}$ during the eruption process.

The three frames of Fig. 7 show the eruption of three consecutive bubbles. Two wake spikes are observed after the eruption of the second and the third bubbles. The first spike has a peculiar geometry, similar to the vortex ring formed from a nozzle during the injection of a water jet [31], while the second spike is more elongated and geometrically more similar to a spike. The bulge of particles between bubbles 1 and 2 are also projected to the freeboard (double bubble mechanism [20]), although this group of particles moving upward collides with the particles raining from the dome of the first bubble, which where previously projected. As a result, Fig. 7(b) shows a very irregular dome in the second bubble, the consequence of the collision of the two groups of particles moving in opposite directions. This effect is more important in 2D geometries, where the movement in the third dimension is limited by the bed walls. In addition, the thickness of the bubble dome in 2D beds at the instant of eruption seems to be wider than in $3 \mathrm{D}$ beds [15,25]; thus, the collision is more important.

Fig. 8(a) and (b) respectively, show the velocity of the first and second wake spikes shown in Fig. 7. In both cases, the displacement of the nose of the spike is followed during the solid projection until it collides with the particles projected from the bubble dome. The results shown in Fig. 8 demonstrate that the ejection velocity in the wake spike mechanism is much higher than in isolated bubbles. The velocity of both spikes is over $1 \mathrm{~m} / \mathrm{s}$ during almost the entire

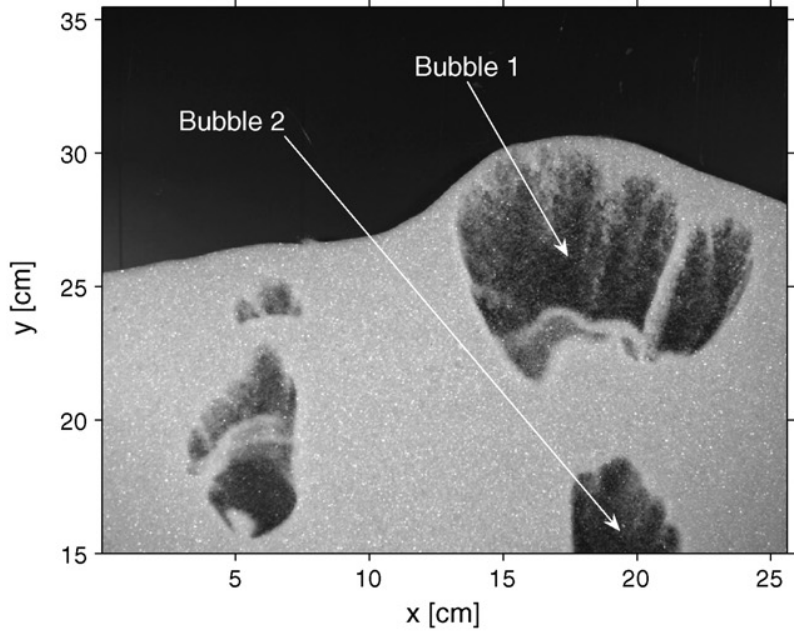

(a) $t=0 \mathrm{~ms}$

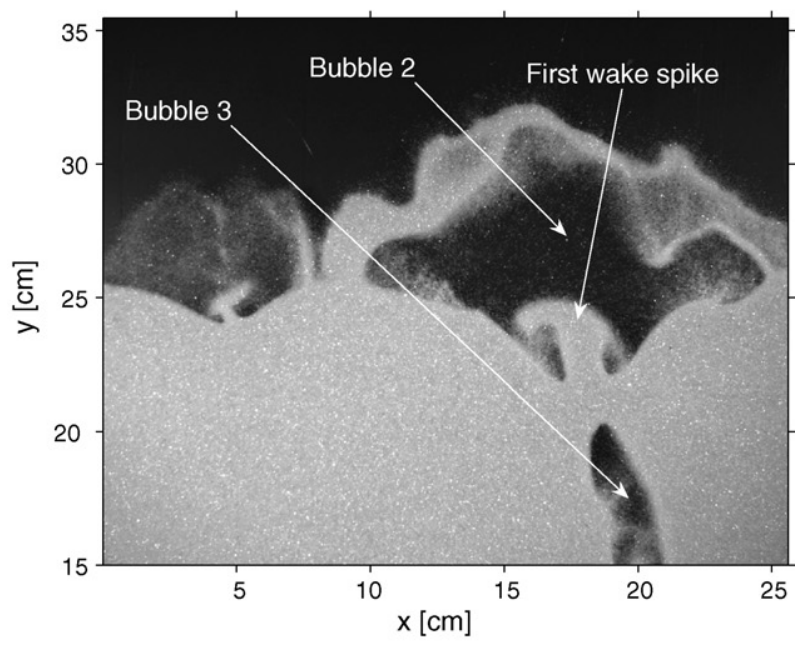

(b) $t=152 \mathrm{~ms}$

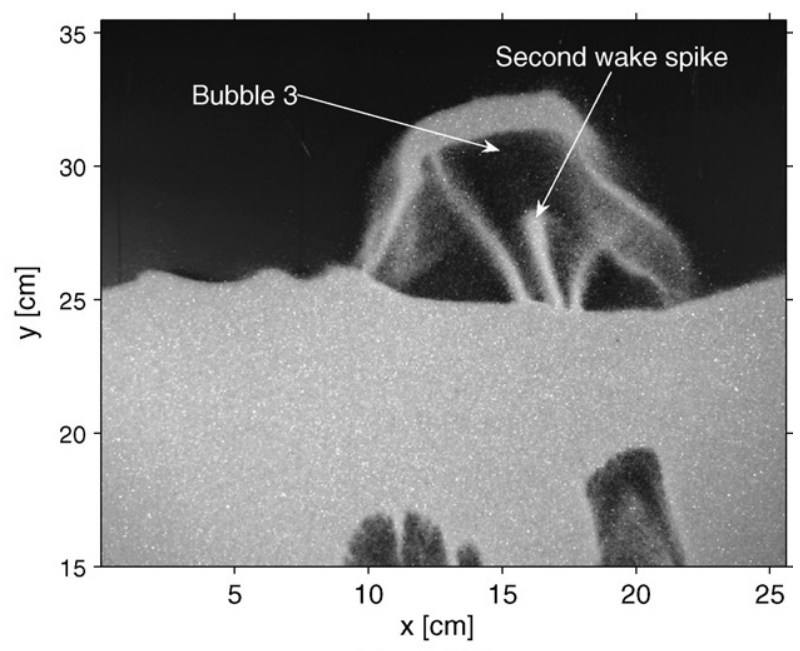

(c) $t=272 \mathrm{~ms}$

Fig. 7. Three consecutive bubbles coalescing at the bed surface with two wake spikes between them: (a) $t=0 \mathrm{~ms}$; (b) $t=152 \mathrm{~ms}$; (c) $t=272 \mathrm{~ms}$ 

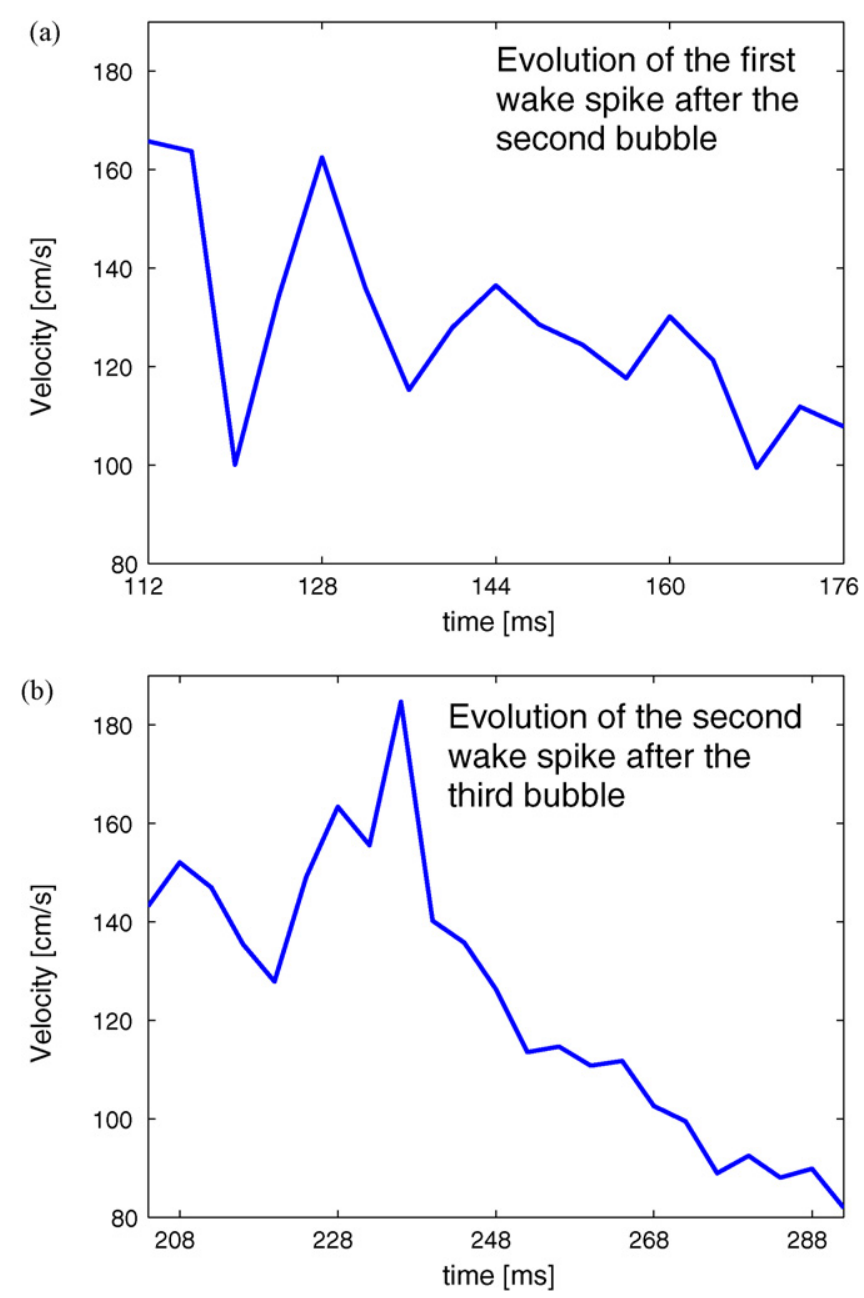

Fig. 8. (a) Velocity of the first wake spike shown in Fig. 7(b) and (b) velocity of the second wake spike shown in Fig. 7(c).

ejection process, while in the case of isolated bubbles, the ejection velocity seldom exceeds $0.5 \mathrm{~m} / \mathrm{s}$. Even with two bubbles coalescing (Fig. 6(b)), the ejection velocity is lower.

The particle ejection velocity in the wake spike mechanism seems to be higher at the initial instant. Then, it decreases progressively until the spike reaches a height where it collides with the particles projected from the dome. The deceleration process is not smooth, and the velocity fluctuates during the ejection process. These irregularities are caused by the continuous rain of particles from the bubble dome.

\section{Jet spike mechanism}

In this solid ejection mechanism, the particles are not projected in a coherent group (a dome or a spike). Instead, the jet spike occurs when a stream of bubbles coalescing at the bed surface forms a channel through which particles are transported and projected from the interior of the bed to the freeboard. The solids form a continuous cloud of particles with a poorly defined geometry. Thus, in order to measure the velocity of the ejected particles in this mechanism, rather than follow the displacement of the contour of a well-defined geometry, Particle image velocimetry (PIV) will be used.

Different works can be found in the literature using PIV in granular flows [32], silo discharge [33-35] and fluidized beds [26,12]. The same PIV software used by Müller et al. [26](MATPIV 1.6.1 [36]) and the same iterative process and filters of this work were followed. A total of $2 \times 10^{4}$ vectors were obtained in each picture, and around $85-90 \%$ of them (depending on the picture) had a signal/noise value higher than 1.3. Müller et al. [26] used MATPIV 1.6.1 to measure the particle velocity around isolated injected bubbles erupting at the surface of a bed at minimum fluidization conditions. In this work, this software will be used to obtain the particle velocity field in the jet spike mechanism for solids ejection in a freely bubbling fluidized bed.

Figs. 9 and 10 show a sequence of six frames captured during the ejection of solids by the jet spike mechanism. A total of 12 bubbles reached the freeboard through the channel opened at the bed surface during $0.7 \mathrm{~s}$. The channel formed diverts the trajectory of most of the flow crossing the bed (either visible flow in the form of bubbles or throughflow) through the opened channel. This effect could cause defluidization in some regions of the bed, particularly in the vicinity of the jet, because the gas flow has been reduced under minimum fluidization conditions. This effect is similar to the one caused by the rat-holes that appear when type $C$ particles are fluidized [22]. The ejection of solids is violent, and the dome and wake of one erupting bubble collides with the particles ejected by the previous ones. As a consequence, the ejected particle velocity is strongly influenced by the collision with other particles and the resulting interchange in momentum between them. Thus, the resulting velocity is not as high as would be expected by solely considering the high pressure gradient between the bottom of the jet and the freeboard, which projects the particles to the freeboard. The highest velocities are observed when the particles moving down return to the bed (see Fig. 10(b)) and at some local points situated in the jet.

Figs. 9 and 10 show the general behaviour of how the particles within the bed are pushed to the interior of the channel by the gas flow. Once the particles are inside the channel, these particles move upward, dragged by the gas flow until they are ejected into the freeboard. In contrast, the particles inside other bubbles located at the left side of the jet (see Figs. 9(c) and 10(a)) move down because of the throughflow in these bubbles cannot drag the raining particles. Müller et al. [26] observed similar results in the interior of isolated injected bubbles erupting at the bed surface. They observed that the particle velocity is zero at a distance of approximately $D_{b} / 4$ from the bubble top. The particles above that point move upward, while those located below it move downward. A similar behaviour was observed in the bubbles not influenced by the jet in Figs. 9 and 10.

\section{Gas mixing in the splash zone induced by bubble bursting}

Although the focus of this work is on the ejection of solids, bubble eruption has also a high influence on gas mixing in the splash zone, which control the conversion rate in gasifiers and combustors of high-volatile solid fuels (e.g. biomass) [37]. Recently, Solimene et al. [38] and Hartung et al. [21] have studied the mixing of gas in the splash zone by means of planar laser-induced fluorescence (PLIF) in isolated and in a stream of injected bubbles. Hartung et al. [21] observed five different eruption patterns, depending on the zone of the bubble dome where the gas is released:

- Release of the gas at an eruption angle of $0^{\circ}$ (also called "nose pocket"), $45^{\circ}$ and $90^{\circ}$ (parallel to the bed surface).

- Even release of gas along the bubble dome.

- No release of gas.

They suggest that the eruption patterns are related with the local thickness of the dome during the eruption process. 


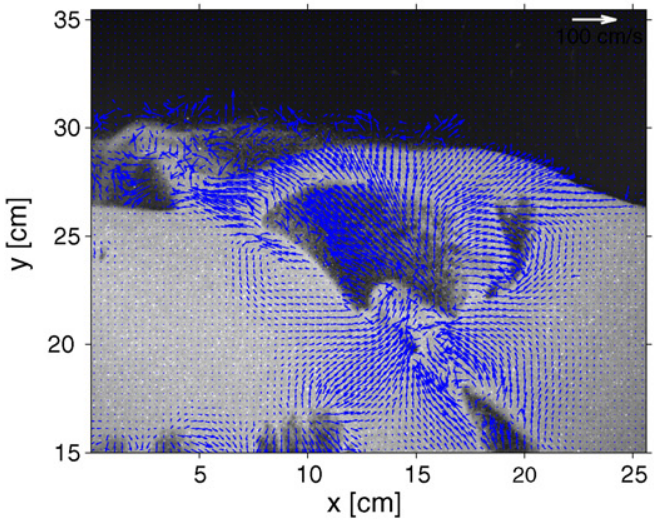

(a) $\mathrm{t}=0 \mathrm{~ms}$

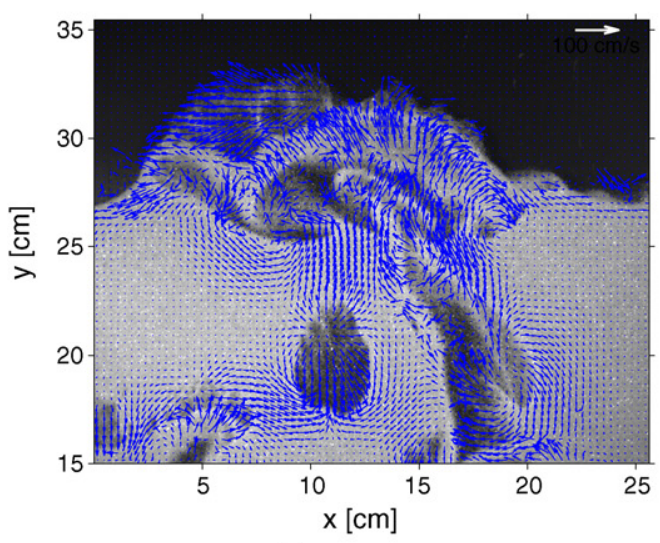

(c) $\mathrm{t}=116 \mathrm{~ms}$

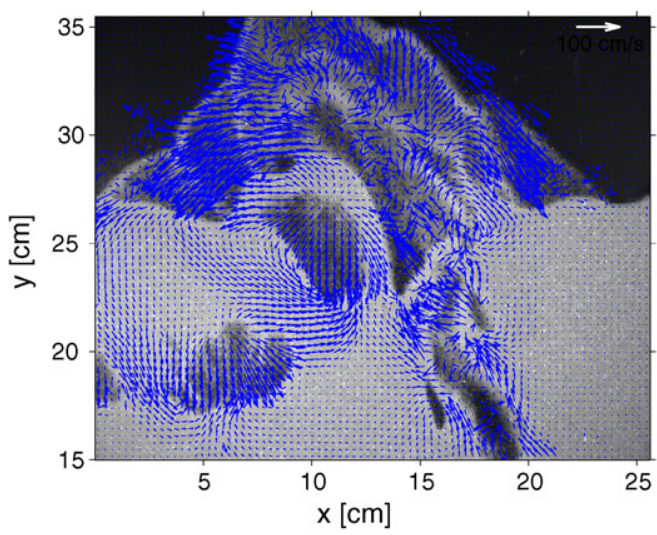

(e) $\mathrm{t}=220 \mathrm{~ms}$

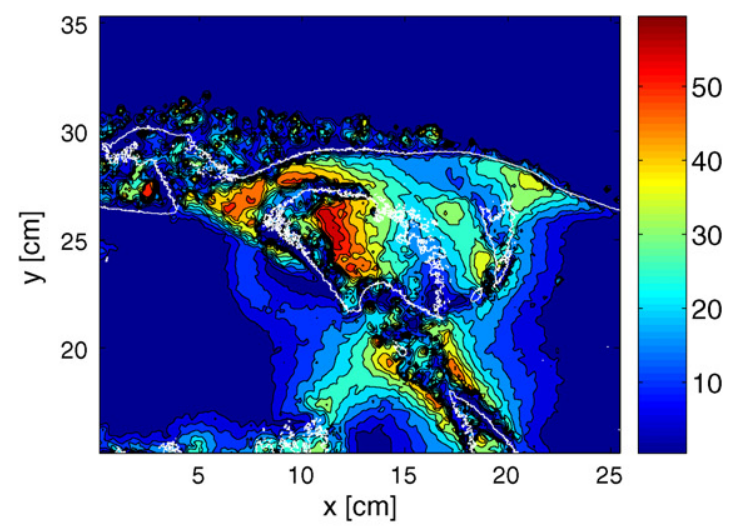

(b) $\mathrm{t}=0 \mathrm{~ms}$

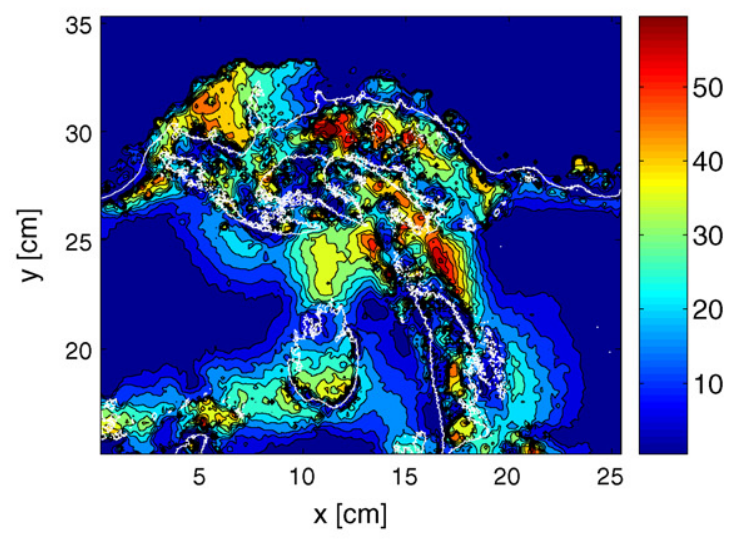

(d) $\mathrm{t}=116 \mathrm{~ms}$

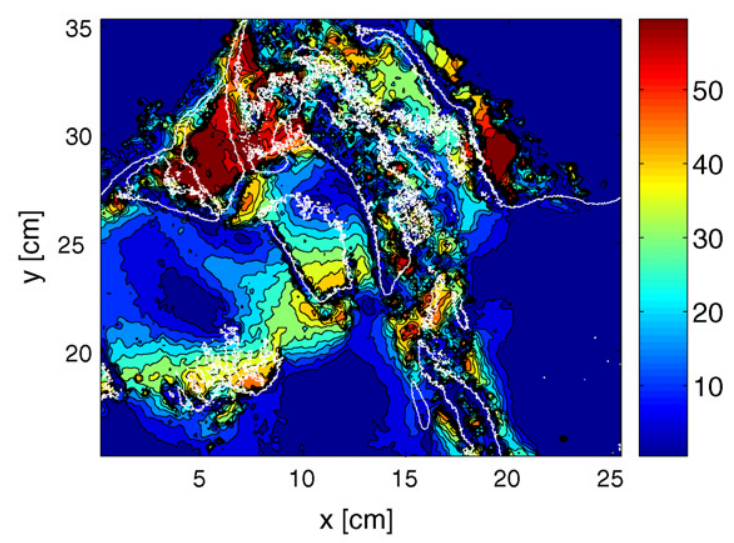

(f) $\mathrm{t}=220 \mathrm{~ms}$

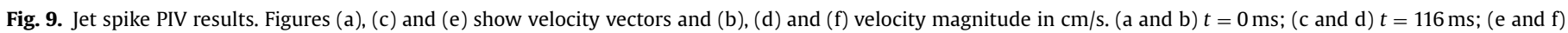
$t=220 \mathrm{~ms}$.

The examples of isolated bubble eruptions showed in this work suggest that the stalactite effect could have a great influence on the eruption patterns described by Hartung et al. [21]. The gas throughflow crossing the bubble leaves the bubble through regions of the dome where stalactites are not present. In this way, when a stalactite appears at the nose of the bubble (see Figs. 2 and 4 ) the gas flow is deviated and breaks the dome forming and angle of $\sim 45^{\circ}$, which is one of the mechanisms observed by Hartung et al. [21]. If the stalactites are not present at the bubble nose, the gas can break the dome through its nose and the formation of a nose pocket is observed in this case (see Fig. 5(e), where the breakage of the nose of the dome is clearly observed.).
The release of gas forming $\sim 90^{\circ}$ can be attributed to bubbles with a collapsed dome, as the ones observed by Almendros-Ibáñez et al. $[13,25]$. These bubbles are almost enterally over the bed surface when the dome collapses. The throughflow crossing the bubble is low and consequently the particles ejection velocity is small. The particles rain from the dome forcing the gas to leave the bubble parallel to the bed surface toward the sides of the collapsed dome and two toroidal vortex are formed at each side. Hartung et al. [21] suggest a similar explanation of this gas release mechanism.

The release of gas uniformly along the dome could be observed when no stalactites are present in the dome or their influence is negligible. If the dome thickness decreases uniformly along the 


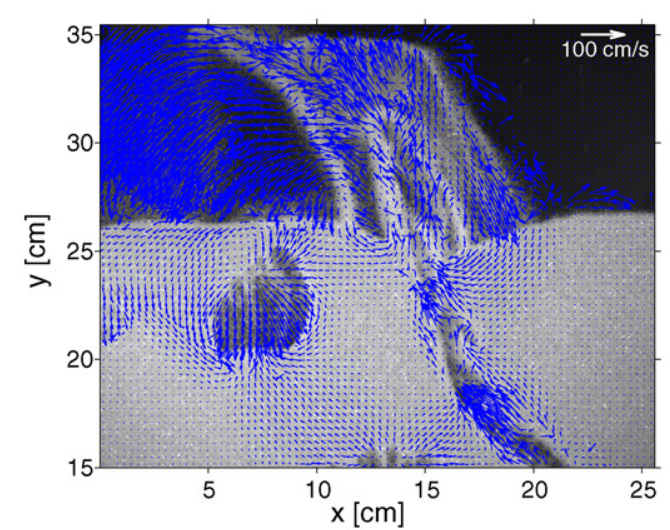

(a) $\mathrm{t}=332 \mathrm{~ms}$

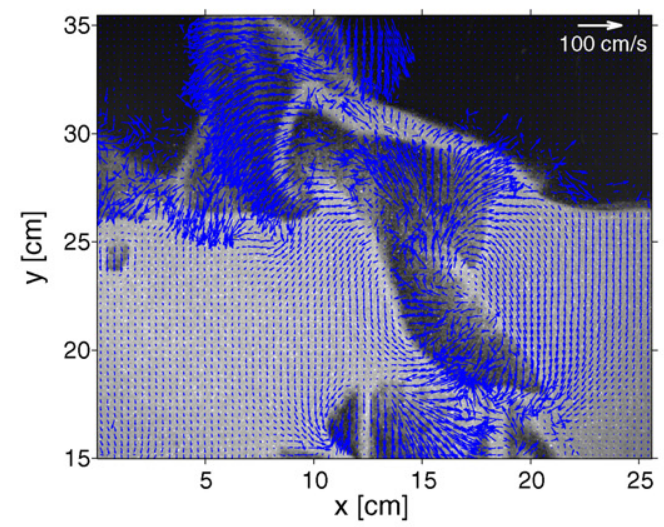

(c) $\mathrm{t}=460 \mathrm{~ms}$

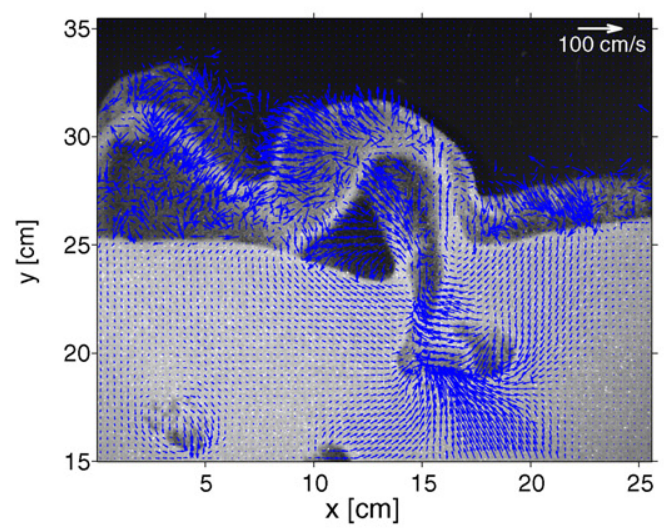

(e) $\mathrm{t}=584 \mathrm{~ms}$

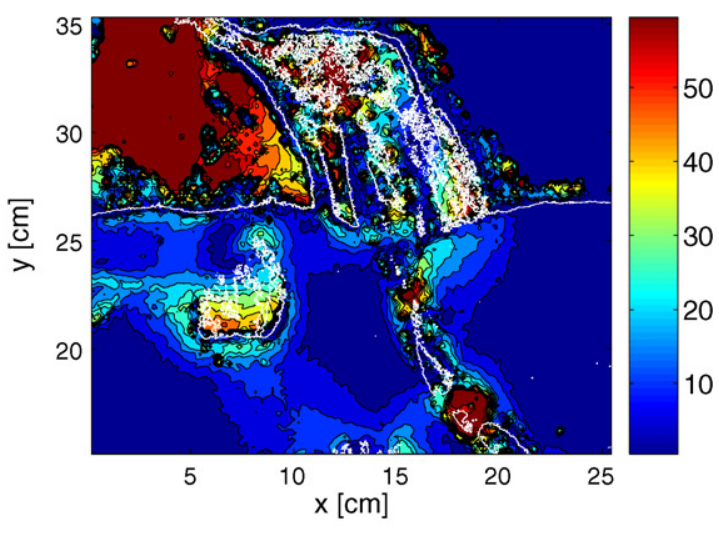

(b) $\mathrm{t}=332 \mathrm{~ms}$

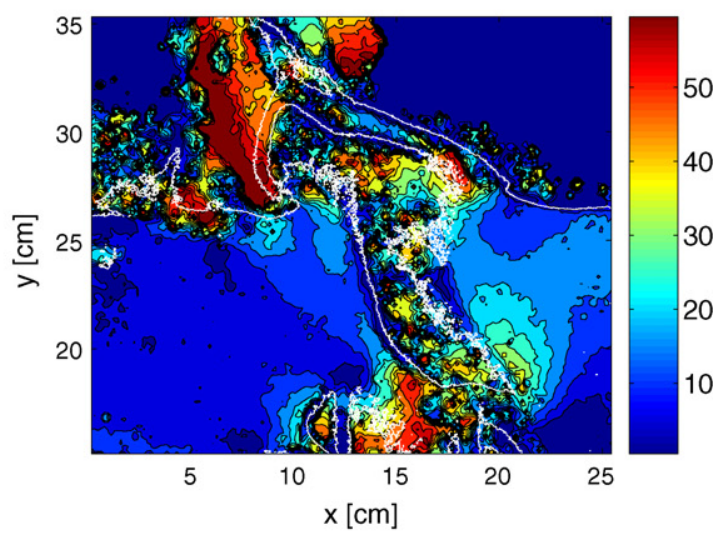

(d) $\mathrm{t}=460 \mathrm{~ms}$

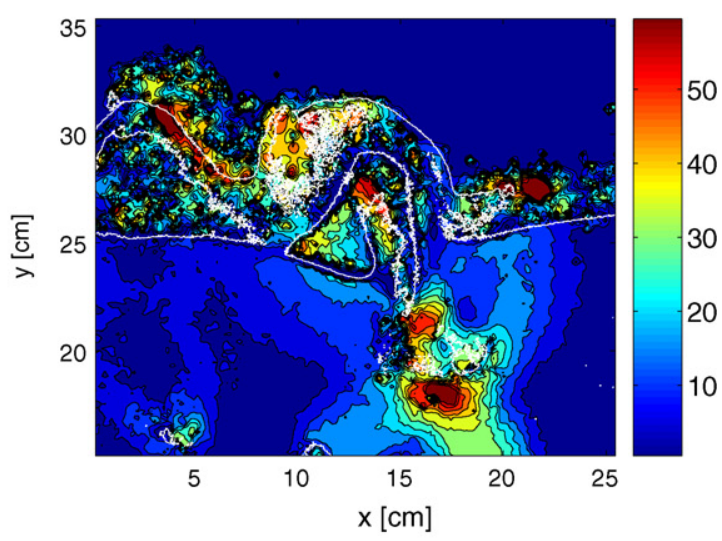

(f) $\mathrm{t}=584 \mathrm{~ms}$

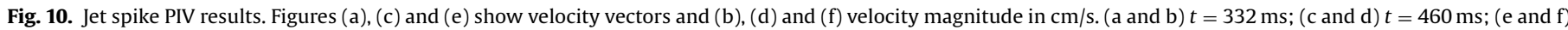
$t=584 \mathrm{~ms}$.

bubble dome, the release of gas should be uniform. This mechanism could be difficult to observe in 2D fluidized beds due to the wall effect favours the formation of stalactites. In contrast, there is no a clear explanation for the last mechanism suggested by Hartung et al. [21]: no release of gas.

The studies published about gas mixing are limited to isolated or a stream of injected bubbles, therefore bubble coalescence is not involved. The gas mixing in the splash zone should be more complex in a freely bubbling fluidized bed, where other solid ejection mechanisms (double bubble, wake spike and jet spike mechanism) are present. More effort is necessary to study the gas mixing in these cases. Also the eruption of different bubbles at the same time at the bed surface, could modify the typical toroidal vortices observed in isolated bubbles.

\section{Discussion and conclusions}

In this work, the particle ejection velocity for different ejection mechanisms has been observed in a 2D bed. The evolution of the dome contour in isolated erupting bubbles, as well as in two coalescing bubbles, were tracked during the eruption process. In the wake spike mechanism the velocity of the nose of the spike was measured, and this mechanism had the highest ejection velocities. In the jet spike mechanism, PIV was used to measure the particle 
ejection velocity because a cloud of dispersed particles is observed rather than a group of particles with a well defined shape.

In isolated erupting bubbles, groups of particles are observed raining in the form of stalactites within the bubble. This effect causes a deceleration in the particles situated just over the stalactites, which result in the typical instabilities at the contour of the bubble dome during the eruption process observed by Müller et al. [26]. In addition, the throughflow crossing the bubble cannot drag the raining particles, and thus, is deviated. Thus, the throughflow drags the particles located at the sides of the dome where the ejection particle velocity has an appreciable horizontal component.

The stalactite effect could also explain some of the different patterns of gas release in isolated erupting bubbles observed by Hartung et al. [21]. The gas leaves the bubble through the regions of the dome where stalactites are not present forming $0^{\circ}$ or $45^{\circ}$. When the stalactite influence is small, the release of gas is uniform along the dome and when the bubble has a "collapsed dome" $[13,25]$ the gas releases the bubble parallel to the bed surface $\left(90^{\circ}\right)$ forming two toroidal vortices.

The general behaviour is different when two or more bubbles coalesce. If the coalescence takes place when the leading bubble approaches the bed surface but still has not broken the bed surface, the momentum of the trailing bubble, together with the increase in the throughflow, accelerate the dome of the leading bubble, and consequently, the ejection velocity increases. In contrast, if coalescence occurs when the interior of the leading bubble is in contact with the freeboard (the dome is broken), then the wake spike mechanism appears: the wake of the trailing bubble is projected with a very high velocity.

In the jet spike mechanism, there is no group of particles with a well-defined geometry. In this mechanism, a cloud of particles is continuously ejected to the freeboard. Thus, the ejection velocity is not as high as in the wake spike mechanism because the momentum of the particles is notably reduced by collisions with other particles. The channel formed during the process forces the bubbles, and also the invisible flow, to reach the freeboard through this channel, and defluidized regions could also appear in the bed.

Levy et al. [20] concluded that around 90\% of the more than 5000 erupting bubbles observed in 2D and 3D fluidized beds were isolated bubbles, and only in $10 \%$ bubble coalescence was involved. Nevertheless, although isolated erupting bubbles are more frequent, the ejection velocity of the solids projected by this mechanism is low. Moreover, when the stalactite effect appears, the vertical velocity of the ejected solids is notably reduced. Thus, the TDH, which can be defined as the highest height reached by the particles of largest size, should be obtained from the ejection mechanism in which higher velocities are observed.

In this work, the highest ejection velocities have been observed when bubble coalescence is involved, especially in the wake spike mechanism. In addition, this mechanism ejects particles from the wake of the bubble where the mean particle size is higher than in the bubble nose (usually fine particles accumulate at the bed surface [8]). Thus, the ejection velocity and the particle sizes are higher, and consequently the solids ejected by this mechanism will reach higher heights in the freeboard $[16,39]$. The maximum height reached by the solids ejected by the wake and jet spike mechanisms cannot be observed experimentally due to the 2D geometry of the experimental facility. The particle movement in the third direction is restricted by the walls of the bed. As a consequence, ejected solids collide with the solids ejected previously from the bubble dome or from previous bubbles before reaching the maximum height. Moreover, the dome thickness in $2 \mathrm{D}$ beds is higher than in 3D beds [8].

In summary, the particle ejection velocity has been observed for different mechanisms of solids ejection. In isolated bubble erup- tion, the dome of the bubble is ejected to the freeboard, although these particles travel at low velocities due to the rain of particles within the bubble in the form of stalactites. In addition, this stalactite effect could explain some of the gas release patterns observed by Hartung et al. [21] in isolated and streams of injected bubbles. When two or more bubbles coalesce, if the coalescence takes place before the leading bubble breaks, the momentum of the trailing bubble together with the increase in the throughflow crossing both bubbles accelerates the dome of the leading bubble. If coalescence occurs when the leading bubble has broken, the wake of the rear bubble is ejected at a very high velocity. Finally, the jet mechanism occurs when a stream of bubbles follows the path opened by the previous one. A cloud of particles moving upward is observed, although their velocity is notably reduced by their collision with other particles.

\section{Acknowledgement}

This work has been supported by the National Energy Programme of the Spanish Ministry of Education under the project number ENE2006-01401.

\section{Appendix A. Nomenclature}

a experimental constant in Eq. (3) $\left[\mathrm{m}^{-1}\right]$

A cross-sectional area of the bed $\left[\mathrm{m}^{2}\right]$

$d_{p} \quad$ particle diameter $[\mathrm{m}]$

$D_{b} \quad$ bubble diameter [m]

E flux of elutriated particles defined by Eq. (2)[ $\left.\mathrm{kg} /\left(\mathrm{s} \mathrm{m}^{2}\right)\right]$

g gravity constant $\left[9.81 \mathrm{~m} / \mathrm{s}^{2}\right]$

$h \quad$ height measured over the bed surface [m]

$H \quad$ length of the bed [m]

$\Delta P_{\text {bed }} \quad$ pressure drop of the gas crossing the bed

$\Delta P_{\text {dist }}$ pressure drop of the gas crossing the distributor

$U \quad$ superficial gas velocity $[\mathrm{m} / \mathrm{s}]$

$v \quad$ particle velocity in the freeboard $[\mathrm{m} / \mathrm{s}]$

\section{Greeks letters}

$\delta \quad$ thickness of the bubble dome at the eruption instant [m]

$\mu \quad$ dynamic gas viscosity $\left[(\mathrm{N} \mathrm{s}) / \mathrm{m}^{2}\right]$

$\bar{\rho} \quad$ mass of particles per unit of bed volume $\left[\mathrm{kg} / \mathrm{m}^{3}\right]$

$\rho_{g} \quad$ gas density $\left[\mathrm{kg} / \mathrm{m}^{3}\right]$

$\rho_{p} \quad$ particle density $\left[\mathrm{kg} / \mathrm{m}^{3}\right]$

\section{Subscripts}

$i \quad$ magnitude referred to a discrete particle size range with a mean particle diameter of $d_{p_{i}}$

$m f \quad$ magnitude referred at minimum fluidization conditions

$0 \quad$ magnitude referred at the bed surface $(h=0)$

$\infty \quad$ magnitude refereed at an height over the TDH

\section{References}

[1] J. Werther, E.U. Hartge, in: W.C. Yang (Ed.), Handbook of Fluidization and FluidParticle Systems, Marcel Dekker Inc., New York, 2003, p. 113.

[2] L. Devi, K.J. Ptasinski, F.J.J.G. Janssen, A review of the primary measures for tar elimination in biomass gasification processes, Biomass Bioenerg. 24 (2003) 125-140.

[3] D. Ross, R. Noda, M. Horio, A. Kosminski, P. Ashman, P. Mullinger, Axial gas profiles in a bubbling fluidised bed biomass gasifier, Fuel 86 (2007) 1417-1429.

[4] D. Santana, J.M. Rodríguez, A. Macías-Machín, Modelling fluidized bed elutriation of fine particles, Powder Technol. 106 (1999) 110-118

[5] D. Kunii, O. Levenspiel, Entrainment of solids from fluidized beds. I. Hold-up of solids in the freeboard. II. Operation of fast fluidized beds, Powder Technol. 61 (1990) 193-206.

[6] C.Y. Wen, L.H. Chen, Fluidized bed freeboard phenomena: entrainment and elutriation, AIChE J. 28 (1982) 117-128. 
[7] T.P.Chen, S.C. Saxena, in: J.F. Davidson, D.L. Keairns (Eds.), Fluidization: Proceedings of the Second Engineering Foundation Conference, Cambridge University Press, London, 1978, p. 151.

[8] S.T. Pemberton, J.F. Davidson, Elutriation from fluidized beds-I. Particle ejection from the dense phase into the freeboard, Chem. Eng. Sci. 41 (1986) 243251.

[9] K. Smolders, J. Baeyens, Elutriation of fines from gas fluidized beds: mechanims of elutriation and effect of freeboard geometry, Powder Technol. 92 (1997) 35-46.

[10] H. Hatano, M. Ishida, The entrainment of solid particles from a gas-solid fluidized bed, J. Chem. Eng. Jpn. 14 (1981) 306-311.

[11] E.K. Levy, J.C. Dille, H.S. Caram, Single bubble eruptions in gas fluidized beds, Powder Technol. 32 (1982) 173-178.

[12] D. Santana, S. Nauri, A. Acosta, N. García, A. Macías-Machín, Initial particle velocity spatial distribution from 2-D erupting bubbles in fluidized beds, Powder Technol. 150 (2005) 1-8.

[13] J.A. Almendros-Ibáñez, C. Sobrino, M. de Vega, D. Santana, A new model for ejected particle velocity from erupting bubbles in 2-D fluidized beds, Chem. Eng. Sci. 61 (2006) 5981-5990.

[14] J.H. Choi, J.E. Son, S.D. Kim, Solid entrainment in fluidized bed combustors, J. Chem. Eng. Jpn. 22 (1989) 597-606

[15] S.C. Saxena, A. Mathur, On the origin of solids projected from the surface of a gas-fluidized bed, Chem. Eng. Sci. 39 (1984) 917-918.

[16] F.A. Zenz, N.A. Weil, A theoretical-empirical approach to the mechanism of particle entrainment from fluidized beds, AIChE J. 4 (1958) 472-479.

[17] J.G. Yates, P.N. Rowe, A model for chemical reaction in the freeboard region above a fluidised bed, Trans. Inst. Chem. Eng. 55 (1977) 137-142.

[18] S.E. George, J.R. Grace, Entrainment of particles from agregative fluidized beds, AIChE Symp. Ser. 74 (1978) 67-74.

[19] C.L. Briens, M.A. Bergougnou, T. Baron, Prediction of entrainment from gas-solid fluidized beds, Powder Technol. 54 (1988) 183-196.

[20] E.K. Levy, H.S. Caram, J.C. Dille, S. Edelstein, Mechanims for solid ejection from gas-fluidized beds, AIChE J. 29 (1983) 383-388.

[21] G. Hartung, C.R. Müller, J. Hult, J.S. Dennis, C.F. Kaminski, Laser diagnostic investigation of the bubble eruption patterns in the freeboard of fluidized beds. 1 Optimization of acetone planer laser induced fluorescence measurements, Ind. Eng. Chem. Res. 47 (2008) 5686-5697.

[22] D. Geldart, Types of gas fluidization, Powder Technol. 7 (1973) 285292.

[23] F. Johnsson, R.C. Zijerveldb, J.C. Schoutenb, C.M. van den Bleek, B. Leckner, Characterization of fluidization regimes by time-series analysis of pressure fluctuations, Int. J. Multiphase Flow 26 (2000) 663-715.
[24] S. Sasic, F. Johnsson, B. Leckner, Fluctuations and waves in fluidized bed systems: the influence of the air-supply system, Powder Technol. 153 (2005) $176-195$.

[25] J.A. Almendros-Ibáñez, C. Sobrino, S. Sánchez-Delgado, D. Santana, M. de Vega U. Ruiz-Rivas, in: X. Bi, F. Berruti, T. Pugsley (Eds.), Fluidization XII: New Horizons in Fluidization Engineering, Engineering Conference International, New York, 2007, p. 169.

[26] C.R. Müller, J.F. Davidson, J.S. Dennis, A.L. Hayhurst, A study of the motion and eruption of a bubble at the surface of a two-dimensional fluidized bed using particle image velocimetry (PIV), Ind. Eng. Chem. Res. 46 (2007) 1642-1652.

[27] U. Gonzales-Barron, F. Butler, A comparison of seven thresholding techniques with the k-means clustering algorithm for measurement of bread-crumb features by digital image analysis, J. Food Eng. 74 (2006) 268-278.

[28] N. Otsu, A threshold selection method from gray-level histograms, IEEE Trans. Syst. Man Cybern. 9 (1979) 62-66.

[29] P.N. Rowe, B.A. Partridge, An X-ray study of bubbles in fluidised beds, Trans. Inst. Chem. Eng. 43 (1965) 157-175.

[30] L.R. Glicksman, T. Yule, in: K. Ostergaard, A. Sorensen (Eds.), Fluidization V: Proceedings of the Engineering Foundation Conference, Amer. Inst. of Chemical Engineers, Elsinore (Denmark), 1986, p. 103.

[31] M. van Dyke, An Album of Fluid Motion, 8th edn., The Parabolic Press, 1982, p 43.

[32] R.M. Lueptow, A. Akonur, T. Shinbrot, PIV for granular flows, Exp. Fluids 28 (2000) 183-186.

[33] J.U. Böhrnsen, H. Antes, M. Ostendorf, J. Schwedes, Silo discharge: measurement and simulation of dynamic behavior in bulk solids, Chem. Eng. Technol. 27 (2004) 71-76.

[34] M. Ostendorf, J. Schewedes, Application of particles image velocimetry for velocity measurements during silo discharge, Powder Technol. 158 (2005) 69-75.

[35] C. Slominski, M. Niedostatkiewicz, J. Tejchman, Application of particle image velocimetry (PIV) for deformation measurement during granular flow, Powder Technol. 173 (2007) 1-18.

[36] J.P. Sveen, http://www.math.uio.no/ jks/matpiv (last modified in August, 2004, accessed in 2008)

[37] B. Leckner, Fluidized bed combustion: mixing and pollutant limitation, Prog. Energy Combust. Sci. 24 (1998) 31-61.

[38] R. Solimene, A. Marzocchella, R. Ragucci, P. Salatino, Laser diagnostics of hydrodynamics and gas-mixing induced by bubble bursting at the surface of gas-fluidized beds, Chem. Eng. Sci. 62 (2007) 94-108.

[39] H.T. Do, J.R. Grace, R. Clift, Particle ejection and entrainment from fluidised beds, Powder Technol. 6 (1972) 195-200. 